\title{
Guidelines proposal for clinical recognition of mouth breathing children
}

\author{
Maria Christina Thomé Pachecoํ․ Camila Ferreira Casagrande², Lícia Pacheco Teixeira 3 , \\ Nathalia Silveira Finck ${ }^{4}$, Maria Teresa Martins de Araújo ${ }^{5}$ \\ DOI: $h t t p: / / d x$. doi.org/10.1590/2176-9451.20.4.039-044.oar
}

Introduction: Mouth breathing $(\mathrm{MB})$ is an etiological factor for sleep-disordered breathing (SDB) during childhood. The habit of breathing through the mouth may be perpetuated even after airway clearance. Both habit and obstruction may cause facial muscle imbalance and craniofacial changes. Objective: The aim of this paper is to propose and test guidelines for clinical recognition of MB and some predisposing factors for SDB in children. Methods: Semi-structured interviews were conducted with 110 orthodontists regarding their procedures for clinical evaluation of $\mathrm{MB}$ and their knowledge about SDB during childhood. Thereafter, based on their answers, guidelines were developed and tested in 687 children aged between 6 and 12 years old and attending elementary schools. Results: There was no standardization for clinical recognition of $\mathrm{MB}$ among orthodontists. The most common procedures performed were inefficient to recognize differences between MB by habit or obstruction. Conclusions: The guidelines proposed herein facilitate clinical recognition of $\mathrm{MB}$, help clinicians to differentiate between habit and obstruction, suggest the most appropriate treatment for each case, and avoid maintenance of mouth breathing patterns during adulthood.

Keywords: Mouth breathing. Airway obstruction. Craniofacial abnormalities.

Introdução: a respiração bucal (RB) é um fator etiológico para os distúrbios respiratórios do sono (DRS) na infância. O hábito de respirar pela boca pode ser perpetuado mesmo depois da desobstrução das vias aéreas. Tanto o hábito quanto a obstrução podem causar desequilíbrios da musculatura facial e alterações craniofaciais. O objetivo deste trabalho é propor e testar uma diretriz para o reconhecimento clínico da RB e de alguns fatores predisponentes aos DRS em crianças. Métodos: entrevistas semiestruturadas foram realizadas com 110 ortodontistas, com relação aos seus procedimentos para avaliação clínica da RB e aos seus conhecimentos sobre DRS na infância. A partir daí, com base nas respostas obtidas, uma diretriz foi desenvolvida e testada em 687 crianças, com 6 a 12 anos, oriundas de escolas de ensino fundamental. Resultados: não existe padronização para o reconhecimento clínico da RB pelos ortodontistas. Os procedimentos mais comumente realizados foram ineficientes para reconhecer a diferença entre a RB por hábito e a por obstrução. Conclusões: a diretriz proposta facilita o reconhecimento clínico da RB, diferencia entre RB por hábito e por obstrução, sugere o tratamento mais adequado para cada caso, e evita a manutenção do padrão de respiração bucal na idade adulta.

Palavras-chave: Respiração bucal. Obstrução das vias respiratórias. Anormalidades craniofaciais.

${ }^{1}$ Full professor, Universidade Federal do Espírito Santo, Department of Clinical Dentistry, Vitória, Espírito Santo, Brazil.

${ }^{2}$ Private practice, Vitória, Espírito Santo, Brazil.

${ }^{3}$ Volunteer professor, Universidade Federal do Espírito Santo, Vitória, Espírito Santo, Brazil.

${ }^{4} \mathrm{MSc}$ in Clinical Dentistry, Universidade Federal do Espírito Santo, Vitória, Espírito Santo, Brazil.

${ }^{5}$ Adjunct professor, Universidade Federal do Espírito Santo, Department of Physiological Sciences, Vitória, Espírito Santo, Brazil.

Submitted: July 04, 2014 - Revised and accepted: January 20, 2015
How to cite this article: Pacheco MCT, Casagrande CF, Teixeira LP, Finck NS, Araújo MTM. Guidelines proposal for clinical recognition of mouth breathing children. Dental Press J Orthod. 2015 July-Aug;20(4):39-44. DOI: http://dx.doi.org/10.1590/2176-9451.20.4.039-044.oar

» The authors report no commercial, proprietary or financial interest in the products or companies described in this article.

» Patients displayed in this article previously approved the use of their facial and intraoral photographs.

Contact address: Maria Christina Thomé Pacheco

Praça Philogomiro Lannes 200 sala 307, Jardim da Penha

CEP: 29.060-740 - Vitória/ES - Brazil - E-mail: christp@terra.com.br 


\section{INTRODUCTION}

Due to its range of comorbidities, mouth breathing $(\mathrm{MB})$ has been a concern for healthcare professionals in various areas. ${ }^{1-4}$ The most common cause of $\mathrm{MB}$ is the presence of obstacles in the nasopharyngeal region, which increases nasal resistance that can be induced by various mechanical factors, including tonsil hyperplasia, hypertrophied turbinates, rhinitis, tumors, infectious or inflammatory diseases, and changes in nasal architecture. ${ }^{2,5}$ However, even after these mechanical factors are removed, $\mathrm{MB}$ continues in most cases due to patient's mouth breathing habit., ${ }^{4,6}$ Unbalanced facial musculature occurs as a result of $\mathrm{MB}$, which causes changes in tooth positioning, lips, tongue, palate, and jaws, so as to counterbalance the new breathing pattern..$^{7-10}$

$\mathrm{MB}$ is one of the most commonly cited characteristics of sleep-disordered breathing (SDB) during childhood, but symptoms are often inadequately recognized. SDB encompasses a wide clinical spectrum, such as snoring, upper airway resistance syndrome (UARS), and obstructive sleep apnea (OSA). ${ }^{11,12}$ Snoring during sleep is estimated to occur among $8 \%$ and $27 \%$ of children, 2\% of which present with OSA. ${ }^{13,14}$ Prevalence of UARS remains unknown and is most likely to be underdiagnosed. Findings for clinical diagnosis of UARS are considered nonspecific, but strongly resemble clinical aspects of chronic mouth breathing and nasal obstruction. ${ }^{15,16,17}$

Dentists may be the first healthcare professionals to have contact with a MB child. Due to the importance of early detection and the need for appropriate treatment, the present study aimed to investigate the perception of $\mathrm{MB}$ by orthodontists, propose guidelines for its clinical recognition, and test the applicability of these guidelines among children aged 6-12.

\section{MATERIAL AND METHODS}

This prospective cross-sectional study was approved by Universidade Federal do Espírito Santo Institutional Review Board under protocol \#162/09. All participants signed an informed consent form before data collection. All procedures were performed by trained and calibrated researchers.

The study was carried out with two distinct populations: orthodontists and children. A sample of 110 orthodontists answered a semi-structured questionnaire about clinical evaluation of respiratory patterns during childhood and their knowledge about SDB in children. Data collection was tabulated and analyzed. Lack of standardization of the procedures employed by orthodontists as well as of diagnostic information in the literature led us to prepare basic guidelines to clinically recognize MB in children (Table 1), based on the most cited procedures.

Guidelines presented in Table 1 were applied to 687 children aged 6-12 years old and attending elementary schools. Only healthy children whose parents gave permission to participate were included.

Children were clinically assessed and received diagnostic impressions as mouth breathers or nose breathers according to their clinical characteristics. Subsequently, they were subjected to three breathing tests selected to assist $\mathrm{MB}$ recognition: the mirror test, the water retention test and the lip seal test. All tests were performed with the child sitting with his/her head straight, keeping his/her lips closed, and breathing normally.

\section{RESULTS}

The procedures most commonly used by orthodontists for clinical diagnosis of a child's breathing pattern were: patient's visual assessment (97.2\%), questions asked to parents or child (87.2\%), and respiratory tests (59\%).

In the visual assessment, orthodontists most often observed whether the child kept his/her lips sealed (97.2\%) and his/her posture (80.0\%). The remaining items observed were: presence of anterior open bite (67.2\%), dark eye circles (63.6\%), long face (63.6\%), gingivitis in anterior maxillary teeth $(50.9 \%)$, posterior cross bite (49\%), and others (25.4\%).

The questions often asked by orthodontists to parents or children were about the position of the lips, whether he/she sleeps or keeps his/her mouth open (90\% and 86.3\%). The remaining questions were about snoring (68.1\%), drools on the pillow (66.3\%), allergies $(62.7 \%)$ whether the child becomes tired easily (59\%), had a cold easily (24.5\%) and others (15.4\%).

The breathing tests most commonly applied by orthodontists to their pediatric patients were the lip seal test $(75.4 \%)$, the mirror test $(56.8 \%)$, and the water retention test (34.5\%). Other tests cited by 5.4\% of orthodontists were placement of cotton under the nostrils and the swallowing test.

In the second phase of the study, 687 children were examined and classified as nose breathers or mouth 
Table 1 - Proposed guidelines for clinical recognition of mouth breathing.

\section{CLINICAL RECOGNITION OF MOUTH BREATHING}

These guidelines can be used to examine children and aid recognition
of mouth breathing
1. Visual assessment

The dentist should assess at least the presence of the following characteristics: With the patient standing

\begin{tabular}{ll} 
» Lack of lip seal & () YES ( ) NO \\
» Posture changes & () YES () NO \\
» Dark eye circles & () YES ( ) NO \\
» Long face & () YES () NO \\
With the patient sited: & \\
\hline " Anterior open bite & () YES () NO \\
" High narrow palate & () YES () NO \\
" Gingivitis in maxillary incisors & () YES () NO \\
2. Questions &
\end{tabular}

Questions should be directed to the child or parents

\section{Do you:}

» Sleep with your mouth open?

() YES () NO

» Keep your mouth open when you are distracted?

() YES () NO

»Snore?

() YES () NO

" Drool on your pillow?

() YES () NO

„Experience excessive daytime sleepiness?

() YES ( ) NO

» Wake up with a headache?

() YES ( ) NO

» Get tired easily?

() YES ( ) NO

» Often have allergies?

() YES () NO

» Often have a stuffy nose and/or runny nose?

() YES ( ) NO

» Have difficulty in school?

() YES () NO

» Have difficulty concentrating?

() YES ( ) NO

\section{Breathing tests}

The child must be sitting. At least two tests should be performed.

\section{a. Graded mirror test}

After the second output of air on the mirror, mark the halo area with a marker (Fig 1).

(Low nasal flow: up to $30 \mathrm{~mm}$; Average nasal flow: 30-60 mm; High nasal flow: above $60 \mathrm{~mm}$ )

\section{b. Water retention test}

Place water in the patient's mouth (approximately $15 \mathrm{ml}$ ) and ask him/her to hold it for 3 minutes.

\section{c. Lip seal test}

Seal the patient's mouth completely with a tape for 3 minutes.

\section{Training to eliminate the habit of mouth breathing}

Training should be performed at home on a daily basis until the child is able to return to nasal breathing

\section{Lip seal test}

Seal the child's mouth with masking tape when he/she is distracted or focusing his/her attention on another activity. Progressively increase the time each day until the child is able to breathe only through the nose for, at least, two consecutive hours.

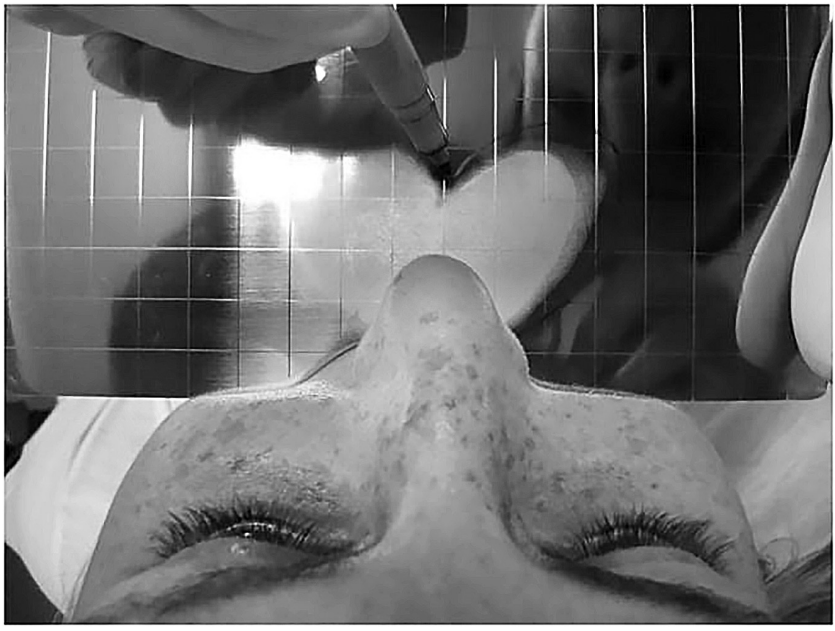

Figure 1 - Marking the steam halo on the graded mirror test.

breathers using the proposed guidelines. The results included in Table 2 present the values for each group.

The absence of lip seal in $35.9 \%$ of mouth breathers and the presence of lip seal in $97.5 \%$ of nose breathers were both statistically significant. The predominant facial pattern in both groups was mesofacial; however, the presence of the dolichofacial pattern was high in the mouth-breather group (34.7\%). Anterior open bite was found among 23.4\% (top and present) of mouth breathers, a greater percentage in comparison to that found for the nose-breather group $(15.8 \%)$. The presence of an atresic palate was significant in the mouth-breather group (53.9\%).

Nearly one third of mouth breathers reported awareness of having problems during their sleep, such as sleeping with their mouth open or drooling on their pillow. Additionally, $18.6 \%$ reported awareness of snoring, whereas $34 \%$ felt daytime sleepiness. Regarding the questions of nasal and allergy problems, $31 \%$ of mouth breathers reported they usually have a runny or stuffy nose, whereas $30.5 \%$ sneezed frequently.

The results for the breathing tests carried out in all children are shown in Table 3.

Children classified as mouth breathers were those who had most severe obstructions (13.8\%) and halos of steam measuring less than $30 \mathrm{~mm}$. For those classified as nose breathers, this percentage was only 1.3\%. Most children diagnosed as mouth breathers presented with bucconasal breathing (85.6\%) and halos of steam greater than $30 \mathrm{~mm}$. 
Table 2 - Prevalence of age group, sex and main characteristics in mouthbreather and nose-breather groups.

\begin{tabular}{|c|c|c|c|c|}
\hline \multirow{3}{*}{ Variable } & \multicolumn{4}{|c|}{ Groups } \\
\hline & \multicolumn{2}{|c|}{ Nose-breather } & \multicolumn{2}{|c|}{ Mouth-breather } \\
\hline & n & $\%$ & $n$ & $\%$ \\
\hline \multicolumn{5}{|l|}{ Age (years) } \\
\hline $6-7$ & 102 & 19.6 & 32 & 19.2 \\
\hline $8-9$ & 218 & 41.9 & 77 & 46.1 \\
\hline $10-11$ & 183 & 35.2 & 48 & 28.7 \\
\hline 12 & 17 & 3.3 & 10 & 6 \\
\hline \multicolumn{5}{|l|}{ Sex } \\
\hline Male & 236 & 45.4 & 90 & 53.9 \\
\hline Female & 284 & 54.6 & 77 & 46.1 \\
\hline \multicolumn{5}{|l|}{ Lip seal } \\
\hline Present & 507 & $97.5^{\star}$ & 107 & 64.1 \\
\hline Absent & 13 & 2.5 & 60 & $35.9^{*}$ \\
\hline \multicolumn{5}{|l|}{ Facial type } \\
\hline Mesofacial & 404 & $77.7^{\star}$ & 100 & 60.5 \\
\hline Dolichofacial & 61 & 11.7 & 58 & $34.7^{\star}$ \\
\hline Brachyfacial & 55 & $10.6^{*}$ & 8 & 4.8 \\
\hline \multicolumn{5}{|l|}{ Open bite } \\
\hline Absent & 437 & $84.1^{*}$ & 128 & 76.6 \\
\hline Top & 40 & 7.7 & 18 & 10.8 \\
\hline Present & 43 & 8.2 & 21 & 12.6 \\
\hline \multicolumn{5}{|l|}{ Palate } \\
\hline Normal & 328 & $63.1^{\star}$ & 77 & 46.1 \\
\hline Atresic & 192 & 36.9 & 90 & $53.9 *$ \\
\hline Total & 520 & 100 & 167 & 100 \\
\hline
\end{tabular}

* statistically significant $(p<0.050)$

Table 3 - Prevalence of breathing tests in mouth-breather (MB) and nosebreather (NB) groups.

\begin{tabular}{|c|c|c|c|c|c|c|}
\hline \multirow{3}{*}{ Variable } & \multicolumn{4}{|c|}{ Groups } & \multirow{2}{*}{\multicolumn{2}{|c|}{ Total }} \\
\hline & \multicolumn{2}{|c|}{ NB } & \multicolumn{2}{|c|}{ MB } & & \\
\hline & n & $\%$ & $n$ & $\%$ & $n$ & $\%$ \\
\hline \multicolumn{7}{|l|}{ Graded mirror test } \\
\hline Halo greater than $30 \mathrm{~mm}$ & 512 & $98.5^{*}$ & 143 & 85.6 & 655 & 95.3 \\
\hline Halo less than $30 \mathrm{~mm}$ & 7 & 1.3 & 23 & $13.8^{*}$ & 30 & 4.4 \\
\hline Test not performed & 1 & 0.2 & 1 & 0.6 & 2 & 0.3 \\
\hline \multicolumn{7}{|l|}{ Lip seal test } \\
\hline 3 minutes & 510 & $98.1^{*}$ & 86 & 51.5 & 596 & 86.8 \\
\hline Less than 3 minutes & 7 & 1.3 & 80 & $47.9 *$ & 87 & 12.7 \\
\hline Test not performed & 3 & 0.6 & 1 & 0.6 & 4 & 0.5 \\
\hline \multicolumn{7}{|l|}{ Water retention test } \\
\hline 3 minutes & 511 & $98.2^{*}$ & 90 & 53.9 & 601 & 87.5 \\
\hline Less than 3 minutes & 5 & 1 & 76 & $45.5^{\star}$ & 81 & 11.8 \\
\hline Test not performed & 4 & 0.8 & 1 & 0.6 & 5 & 0.7 \\
\hline TOTAL & 520 & 100 & 167 & 100 & 687 & 100 \\
\hline
\end{tabular}

* statistically significant $(p<0.050)$
For children classified as mouth breathers, the lip seal test and the water retention test were important in helping to diagnose whether $\mathrm{MB}$ was by habit or obstruction. Table 3 shows that half the group of mouth breathers were MB by habit. They could keep their lips sealed for up to 3 minutes $(51.5 \%$ in the lip seal test and $53.9 \%$ in the water retention test).

\section{DISCUSSION}

Although many articles describe the consequences of $\mathrm{MB},{ }^{1,2,6,11}$ few studies investigate the key parameters for clinical recognition of $\mathrm{MB}$, especially in children.

The orthodontists interviewed for the present study consider the presence of sealed lips and the posture of the child as the most important aspects in determining whether a child is a mouth breather or nose breather. The presence of sealed lips in most children comprising the nose breather group and a statistically significant absence of sealed lips in the mouth-breather group were also found using the proposed guidelines. The agreement between the diagnostic impression of orthodontists and the clinical verification of the item "lack of lip seal" has also been shown in other studies. ${ }^{6,7,18}$

Felcar et $\mathrm{al}^{7}$ found absence of sealed lips in 58.8\% of mouth breathers, and sagging and hypofunction of the orbicularis oris muscle were considered causes of lack of lip seal in $67 \%$ of mouth breathers. ${ }^{18}$ Absence of sealed lips suggests the presence of vertical and sagittal facial discrepancies, inadequate lip length, increased lower facial height, abnormal breathing function, and altered lip tonicity. Increased lower facial height, a characteristic of the dolichofacial type, was also found in the present study. The presence of the dolichofacial type was statistically significant in the mouth-breather group.

The most prevalent malocclusions found in the mouth-breather group were atresic palate and anterior open bite. Several studies have confirmed the close relationship established between teeth, supporting tissues and the functional activity of the neuromuscular system..$^{6,9,19,20}$ When abnormal pressure of muscles interferes in facial growth, it can determine the appearance of a malocclusion. The tongue can take a low and forward position, which is common in the presence of hypertrophic palatine tonsils as an attempt to increase posterior airway space and ease breathing. The low position of the tongue decreases internal pressure in the upper arch, increasing 
the external pressure of perioral muscles and causing an atresic palate. ${ }^{6,10,19,20}$ Because imbalance can cause anatomical and functional changes, proper balance between bones, muscles, and dental structures is essential.

In our study, most orthodontists asked whether the child had allergies. Regular allergic episodes are noteworthy and should be considered in the diagnosis. Temporary, but repeated obstruction of the upper airway can create the habit of breathing through the mouth. Most children with OSA have difficulty breathing through the nose. Allergic rhinitis is the most commonly cited disease, followed by hypertrophy of the tonsils and adenoids. ${ }^{21}$

By applying the guidelines to mouth breathers, we realized that nasal problems and sleep problems were the most relevant. Mouth breathers reported having nasal problems and awareness that they usually snore at night. Rates of snoring vary widely in the literature, depending on the age group studied or the questionnaire employed. Petry et $\mathrm{l}^{12}$ found a prevalence of $27.6 \%$ of habitual snoring, higher than what we found in the present study.

In assessing sleep-related problems, mouth breathers answered they wake up during the night, wake up with a dry mouth, and feel sleepy during the day. Popoaski et $\mathrm{al}^{21}$ reported a percentage of sleep problems of $37.7 \%$, close to what was found in our study. These issues demonstrate the importance of asking patients about sleep and nasal problems during evaluation of mouth breathers. ${ }^{22}$

The mirror test and the water retention test are among the breathing tests most cited in the literature. ${ }^{2,7,15,23-26}$ However, these tests are not standardized and are described with little or divergent information in different publications. ${ }^{2,26}$ The lip seal test is not well described in the literature. In our study, breathing tests were hardly ever used by orthodontists, with no uniformity in the evaluation time for lip seal or water retention tests and lack of agreement on the manner of application of these tests. The lip seal test was the most frequently used, followed by the mirror test and the water retention test.

In order to standardize the breathing tests, we choose an evaluation time of 3 minutes. ${ }^{26}$ The choice of this longer period of time is justifiable because a mouth breather, even when the condition occurs due to obstruction, may breathe through the nose for a short period of time depending on the level of nasal obstruction. Breathing tests are useful to differential diagnosis, as they aid clinicians to decide on the most appropriate treatment modality.

The habit of breathing through the mouth, even without obstruction, alters the balance of facial muscles and causes the same facial skeletal changes that occur among MB due to obstruction.

The presence of $\mathrm{MB}$ by habit was also found in our study. Approximately half the group of mouth breathers managed to keep their lips sealed for up to 3 minutes during the lip seal test and the water retention test. Our guidelines provide orientation on how to restore the nasal breathing pattern of these children by performing the lip seal test every day at home for progressively longer periods each day.

When only a single breathing test is used, results are considered unreliable to determine whether the child is a mouth or nose breather. As guidance, this study suggests the use of at least two breathing tests together - the mirror test in combination with the water retention test or the lip seal test - so as to minimize errors in the recognition of a child's breathing pattern.

With a view to supplementing our diagnostic approach to $\mathrm{MB}$ and its immediate or delayed consequences that may lead to $\mathrm{SDB}$, we observed that most orthodontists had some knowledge about SDB in adults. Currently, treatment of snoring and sleep apnea in adults has been widely included in several courses for dentists. However, childhood SDB presents characteristics that are quite different from SDB in adults. ${ }^{3,13,27}$ The presence of SDB, particularly snoring and OSA, is fairly significant among the pediatric population. ${ }^{3}$ UARS is highly prevalent during childhood, but it is little known by healthcare professionals. ${ }^{11,27}$ Questions about daytime sleepiness and difficulty concentrating at school should also be incorporated into the questionnaire. ${ }^{13}$

Attention deficit hyperactivity disorder (ADHD) is commonly found among MB children. When assessing children with ADHD and complaints about school underachievement, Costa et a ${ }^{15}$ found characteristics of snoring, nocturnal $\mathrm{MB}$, rhinitis, tonsillitis, drool on the pillow, dark circles, and dry lips in more than half of their sample. Both ADHD and MB can trigger SDB, which, together with daytime sleepiness, directly interferes in school performance. ${ }^{1,15}$ 
The guidelines proposed herein should be used as reminders. Due to the importance of these disorders, we emphasize the need for early recognition of signs of SDB in children in order to minimize the occurrence of associated disorders in adulthood.

\section{CONCLUSIONS}

To achieve clinical recognition of mouth breathing $(\mathrm{MB})$, it is important for orthodontists to integrate results yielded by visual assessment, questions, and at least two types of breathing tests. It is essential to ask questions that help identify predisposing factors for sleep-disordered breathing in children. The proposed guidelines may favor the clinical recognition of $\mathrm{MB}$ in children, help differentiate between $\mathrm{MB}$ caused by habit or by obstruction, guide the clinician to choose the most appropriate treatment modality, and prevent adaptive facial changes that perpetuate the MB pattern.

\section{Author contributions}

Conceived and designed the study: MTMA. Acquisition, analysis or interpretation: CFC. Drafting of the study: CFC. Data collection: CFC, LPT, NSF. Wrote the article: LPT. Critical revision of the article: MCTP. Final approval of the article: MCTP. Statistical analysis: NSF. Obtained funding: MTMA.
1. Junqueira P, Marchesan IQ, de Oliveira LR, Ciccone E, Haddad L, Rizzo MC. Speech-language pathology findings in patients with mouth breathing: multidisciplinar diagnosis according to etiology. Int J Orofacial Myology 2010;36:27-32

2. Cunha DA, Silva GAP, Motta MEFA, Lima CR, Silva HJ. Mouth breathing in children and its repercussions in the nutritional state. Rev CEFAC. 2007;9(1):47-54.

3. Okuro RT, Morcillo AM, Sakano E, Schivinski CIS, Ribeiro MAG, Ribeiro JD. Exercise capacity, respiratory mechanics and posture in mouth breathers. Braz J Otorhinolaryngol. 2011;77(5):656-62.

4. Menezes VA, Cavalcanti LL, Albuquerque TC, Garcia AFG, Leal RB. Mouth breathing within a multidisciplinary approach: perception of orthodontists in the city of Recife, Brazil. Dental Press J Orthod. 2011;16(6):84-92

5. Zastrow MD, Grando LJ, Carvalho AP, Ratb IBS, Calvo MC. A comparative study of the breathing pattern and amount of nasopharynx obstruction by the pharyngeal tonsil in HIV infected and non-infected children. Braz J Otorhinolaryngol. 2007:73(5):583-91.

6. Harari D, Redlich M, Miri S, Hamud T, Gross M. The effect of mouth breathing versus nasal breathing on dentofacial and craniofacial development in orthodontic patients. Laryngoscope. 2010;120(10):2089-93.

7. Felcar JM, Bueno IR, Massan ACS, Torezan RP, Cardoso JR. Prevalence of mouth breathing in children from an elementary school. Ciênc Saúde Coletiva 2010;15(2):437-44.

8. Berwig LC, Silva AMT, Busanello AR, Almeida FL, Bolzan GP, Hennig TR, Krob CFO. Alterations in breathing mode, occlusion and speech in school-age children: occurrences and relationships. Rev CEFAC. 2010;12:795-802.

9. Iwasaki T, Saitoh I, Takemoto Y, Inada E, Kanomi R, Hayasaki H, et al., Evaluation of upper airway obstruction in Class II children with fluid-mechanical simulation. Am J Orthod Dentofacial Orthop. 2011;139(2):e135-45.

10. Alves M Jr, Baratieri C, Nojima LI, Nojima MCG, Ruellas ACO. Three-dimensional assessment of pharyngeal airway in nasal- and mouth-breathing children. Int J Pediatr Otorhinolaryngol. 2011;75(9):1195-9.

11. Guilleminault C, Winkle R, Korobkin R, Simmons B. Children and nocturnal snoring: evaluation of the effects of sleep related respiratory resistive load and daytime functioning. Eur J Pediatr. 1982;139(3):165-71.

12. Petry C, Pereira MU, Pitrez PMC, Jones MH, Stein RT. The prevalence of symptoms of sleep-disordered breathing in Brazilian schoolchildren. J Pediatr. 2008:84(2)123-9

13. Izu SC, Itamoto CH, Pradella-Hallinan M, Pizarro GU, Tufik S, Pignatari S, et al. Obstructive sleep apnea syndrome (OSAS) in mouth breathing children. Braz J Otorhinolaryngol. 2010;76(5):552-6.
14. Valera FCP, Demarco RC, Anselmo-Lima WT. Obstructive sleep apnea syndrome (OSAS) in children. Sleep. 1996:19(10 Suppl):S274-7.

15. Costa TLS, Campos Júnior D, Silva HJ, Cunha DA. Symptoms and signs of mouth breathing in teenagers with attention deficit hyperactivity disorder and with complaints about school underachievement. Rev CEFAC. 2009:11(4):607-17

16. Guilleminault $C$, Khramtsov A. Upper airway resistance syndrome in children: a clinical review. Semin Pediatr Neurol. 2001:8(4):207-15.

17. Palombini L, Lopes MC, Tufik S, Guilleminault C, Bittencourt LRA. Upper airway resistance syndrome: still not recognized and not treated. Sleep Science 2001;4(2):72-8.

18. Cattoni DM, Fernandes FDM, Di Francesco RC, Latorre MRDO. Characteristics of the stomatognathic system of mouth breathing children: anthroposcopic approach. Pro Fono. 2007:19(4):347-51

19. Di Francesco RC, Passerotii G, Paulucci B, Miniti A. Mouth breathing in children: different repercussions according to the diagnosis. Braz J Otorhinolaryngol. 2004;70(5):665-70

20. Yilmaz F, Sagdiç D, Karaçay S, Akin E, Bulakbasi N. Tongue movements in patients with skeletal Class II malocclusion evaluated with real-time balanced turbo field echo cine magnetic resonance imaging. Am J Orthod Dentofacial Orthop. 2011;139(5):e415-25

21. Popoaski C, Marcelino TF, Sakae TM, Schmitz LM, Correa LHL. Evaluation from the quality of life in the oral breathers' patients. Arq Int Otorhinolaryngol. 2012:16(1):74-81.

22. Tsuda H, Fastlicht S, Almeida FR, Lowe AA. The correlation between craniofacial morphology and sleep-disordered breathing in children in an undergraduate orthodontic clinic. Sleep Breath. 2011;15(2):163-71

23. Pochat VD, Alonso N, Mendes RRS, Cunha MS, Menezes JVL. Nasal patency after open rhinoplasty with spreader grafts. J Plast Reconstr Aesthet Surg. 2012;65(6):732-8.

24. Brescovici S, Roithmann R. Modified glatzel mirror test reproducibility in the evaluation of nasal patency. Braz J Otorhinolaryngol. 2008;74(2):215-22.

25. Motta LJ, Bachiega JC, Guedes CC, Laranja LT, Bussadori SK. Association between halitosis and mouth breathing in children. Clinics (Sao Paulo). 2011;66(6):939-42

26. Menezes VA, Leal RB, Moura MM, Granville-Garcia AF. Influence of socioeconomic and demographic factors in determining breathing patterns: a pilot study. Braz J Otorhinolaryngol. 2007;73(6):826-34

27. Guilleminault C, Lee JH, Chan A. Pediatric obstructive sleep apnea syndrome Arch Pediatr Adolesc Med. 2005;159(8):775-85. 